\title{
Reforming study of the financial spending policies of China's state general administration of sports
}

Jun Liu

Department of Physical Education, Dalian Polytechnic University, Dalian 116034, China

\begin{abstract}
The paper carries on weight calculation and order of word and combinations by using the analytic hierarchy process through computer operation ability according to determined index system of fiscal spending table made by China's state general administration of sports, and get the weight index of the financial expenditure at all levels. So that we can determine the reasonable allocation of fiscal funds, and compare the allocation proportion with the financial capital expenditure statistics results of 2012, so we find out problems of fiscal expenditure, and then puts forward reforming suggestions of the financial expenditure policy made by the state sport general administration.
\end{abstract}

\section{Introduction}

China's state general administration of sports is the core part of the national sports development leadership department, its main responsibility is to make development strategies related to sports, and plans every link of the whole sports, which helps promoting the development of national sports. China's state general administrations of sports' duties are regulating the important hands, short financial fund allocation and policy making [1-5]. The funds in different sports expenditure play an important role in the development of sports of the related department. A reasonable proportion of fiscal expenditure is of great significance on the development of sports system [6-9].

In this paper, on the basis of previous studies and the reference of China's state general administration of sports of fiscal expenditure statement statistics, we establishes a hierarchy of sports expenditure indexes to study the index weights based on the analytic hierarchy process. By calculating the index weights of fiscal expenditure, we study the rationality of the fiscal policy and make recommendations for the financial policy [10].

\section{The current spending situation of national sports}

According to China's sports bureau's data of the fiscal expenditure budget from 2008-2014 we draw a columnar Figure 1 (which failed to get the relevant data of 2010).

The Sports budget in 2012 was bigger, and the rates in 2012-2014 grow steadily. China's general administration of sport had made statistical analysis in 2006-2008 of the national sports of the related industry, on the basis of these studies, we begin increase the investment to the sports industry in 2012 especially the education investment growth is the largest, from 153 million Yuan in 2008 to 636 million Yuan in 2014.

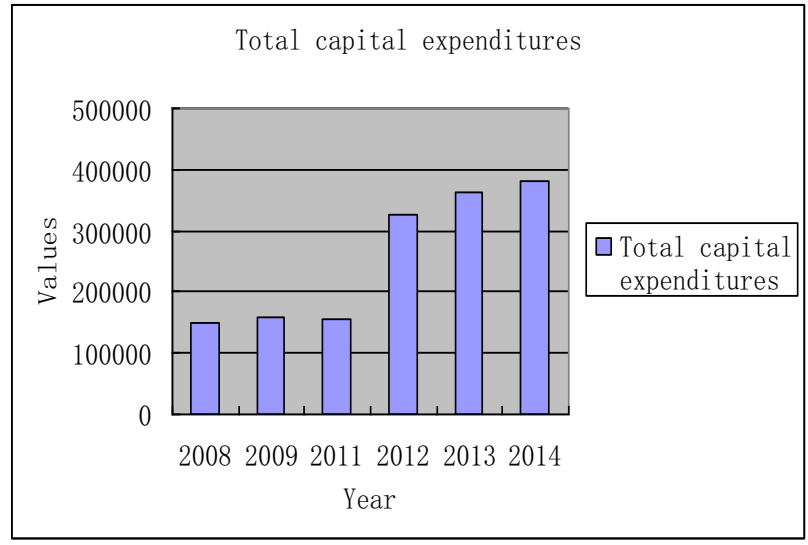

Figure 1. The changes of the financial capital expenditures budget.

According to the fiscal expenditure Table 1 made by China's state general administration of sports, we establish the classification index system, as shown in the follows.

Table 1 shows the index of some cover index, some are not covered. Omit the other item of expenditure in data, and build mainly according to the subject of finance expenditure, finally we calculate the weight.

\section{Using analytic hierarchy process to calculate the index weight}

\subsection{Construct judgment matrix}

a Corresponding author: JunLiu000@qq.com 
Mainly through the interview of the experts and scholars, we describe important degree of the indicators with quantitative values. We use $F_{i}$ to represent the first level, and construct judgment matrix of diplomacy, education, science and technology, sports culture and media, social security and employment, housing security. Then take $C_{i}, C_{j}$ to be compared of the important structure and use get $a_{i j}$ to represents its result. We can get the judgment matrix A. It is shown in the following:

$$
A=\left(\begin{array}{cccc}
a_{11} & a_{12} & \cdots & a_{1 j} \\
a_{21} & a_{22} & \cdots & a_{2 j} \\
\vdots & \vdots & \ddots & \vdots \\
a_{i 1} & a_{i 2} & \cdots & a_{i j}
\end{array}\right)
$$

$a_{i j}$ the quantitative values represent importance of the comparing results, it meaning is shown in the Table 2.

Through the above methods of the first level, we get the judgment matrix. It is shown in Table 3.

Table 1. The financial expenditure of index system.

\begin{tabular}{cccc}
\hline & First level & & Second level \\
Serial number & Subjects & Serial number & Subjects \\
\hline 202 & Diplomacy & & \\
205 & Education & & \\
206 & Science and technology & 20603 & Application research \\
& & 20604 & Technology research and development \\
& & 20605 & Science and technology condition and services \\
207 & Sports culture and media & 20699 & Other spending of science and technology \\
208 & Social security and employment & 20805 & Physical education \\
221 & The spending of housing security & 22102 & The reiteration administrative institution \\
& & & The spending of housing reformation
\end{tabular}

Table 2. The meaning of 1 9 scale.

\begin{tabular}{cc}
\hline scale & meaning \\
\hline 1 & Two factors of the target are equally important \\
3 & The former factor is slightly important than the next one \\
7 & The former factor is important than the next one \\
9 & The former factor is more important than the next one \\
even number & The former factor is much more important than the next one \\
reciprocal & represent the importance between the two Odd numbers \\
& Represent the order of the front-to-back ratio of the factors \\
\hline
\end{tabular}

Table 3. Judgment matrix $F$.

\begin{tabular}{l|llllll} 
& $F_{1}$ & $F_{2}$ & $F_{3}$ & $F_{4}$ & $F_{5}$ & $F_{6}$ \\
\hline$F_{1}$ & 1 & $1 / 7$ & $1 / 5$ & $1 / 9$ & $1 / 3$ & $1 / 2$ \\
$F_{2}$ & 7 & 1 & 2 & 1 & 3 & 4 \\
$F_{3}$ & 5 & $1 / 2$ & 1 & $1 / 2$ & 3 & 3 \\
$F_{4}$ & 9 & 1 & 2 & 1 & 7 & 7 \\
$F_{5}$ & 3 & $1 / 3$ & $1 / 3$ & $1 / 7$ & 1 & 1 \\
$F_{6}$ & 2 & $1 / 4$ & $1 / 3$ & $1 / 7$ & 1 & 1
\end{tabular}

Table 4. RI value list.

\begin{tabular}{ccccccccccccc}
\hline $\mathrm{n}$ & 1 & 2 & 3 & 4 & 5 & 6 & 7 & 8 & 9 & 10 & 11 \\
\hline $\mathrm{RI}$ & 0 & 0 & 0.58 & 0.90 & 1.12 & 1.24 & 1.32 & 1.41 & 1.45 & 1.49 & 1.51 \\
\hline
\end{tabular}

\subsection{The calculation of weight vector and maximum eigenvalues}

We normalize the column vector of judgment matrix primary index, and after adding every row, we begin normalization, the weight vector can be obtained [11]. 
The weight vector of the primary index: $w=\left(\begin{array}{llllll}0.034 & 0.282 & 0.177 & 0.368 & 0.074 & 0.064\end{array}\right)^{T}$

The calculation of the maximum eigenvalues, we know that: $A w=\lambda_{\text {max }} w$

So: $\lambda_{\max }=6.100$

\subsection{Consistency check}

The consistency of judgment matrix $C I$, and Judgment matrix consistency ratio $C R$, computational formula is in the following:

$$
C I=\frac{\lambda_{\max }-n}{n-1}
$$

Among them $n$ represents the Order number of the judgment matrix, also means the number of comparisons:

$$
C R=\frac{C I}{R I}
$$

Among them $R I$ represents the number of Random Consistency Index, which is shown in the Table 4 .

When $C R \geq 0.1$, we think that the inconsistency of judgment matrix appears and need to adjust it. when $C R<0.1$, the inconsistency of the matrix is in an acceptable condition and we can go on calculating. And we calculate the overall level of sorting and consistency check further more.
After calculation we get: $C I=0.0201$, $C R=0.0162<0.1$

So there is no logical problem of the weight of index calculation results.

\subsection{The weight calculation of secondary index}

As for the child pointer of the indexes which has only one index, its index weight is the higher weight value. We build up the matrix of the four child pointers and get its weight. The judgment matrix is shown in Table 5.

The calculation of maximum eigenvalues, weight vector and the check results are in the following;

$$
\begin{aligned}
& \lambda_{\text {max }}=4.0102 \\
& w=\left(\begin{array}{llll}
0.296 & 0.535 & 0.109 & 0.060
\end{array}\right)^{T} \\
& C I=0.0034 \quad C R=0.0038<0.1
\end{aligned}
$$

Calculate the third-level index of sports culture and media respectively. And calculate the sports media spending and indicators of other culture structure matrix and get its weight:

\begin{tabular}{|c|c|c|c|}
\hline \multicolumn{2}{|l|}{ First level } & \multicolumn{2}{|l|}{ Second level } \\
\hline Subjects & Weights & Subjects & Weights \\
\hline Diplomacy & 0.034 & & 0.034 \\
\hline Education & 0.282 & & 0.282 \\
\hline Science and technology & 0.177 & Application research & 0.052 \\
\hline & & Technology research and development & 0.095 \\
\hline & & Science and technology condition and services & 0.019 \\
\hline & & Other spending of science and technology & 0.011 \\
\hline Sports culture and media & 0.368 & Physical education & 0.368 \\
\hline $\begin{array}{l}\text { Social security and } \\
\text { employment }\end{array}$ & 0.074 & The reiteration administrative institution & 0.074 \\
\hline $\begin{array}{l}\text { The spending of housing } \\
\text { security }\end{array}$ & 0.064 & The spending of housing reformation & 0.064 \\
\hline
\end{tabular}

$$
\begin{aligned}
& \lambda_{\text {max }}=4.0102 \\
& w=\left(\begin{array}{llll}
0.296 & 0.535 & 0.109 & 0.060
\end{array}\right)^{T} \\
& C I=0.0034 \quad C R=0.0038<0.1
\end{aligned}
$$

Table 5. The judgment matrix $F_{3}$.

\begin{tabular}{lllll}
\hline$F_{3}$ & $C_{1}$ & $C_{2}$ & $C_{3}$ & $C_{4}$ \\
$C_{1}$ & 1 & $1 / 2$ & 3 & 5 \\
$C_{2}$ & 2 & 1 & 5 & 8 \\
$C_{3}$ & $1 / 3$ & $1 / 5$ & 1 & 2 \\
$C_{4}$ & $1 / 5$ & $1 / 8$ & $1 / 2$ & 1 \\
\hline
\end{tabular}

Table 6. The calculation results of Index weight.

\subsection{The order of the weighting calculation}

If there have $m$ weight factors in one layer and its result is $\alpha_{m}$, the corresponding consistency index is $C I_{m}$, and in the next layer $\mathrm{A}$, there have $\mathrm{n}$ weight factors, and its result is $\beta_{n m}$, so the total ordering weights in the layer $\mathrm{B}$ 
is: $w_{i}=\sum_{j=1}^{m} \alpha_{i} \beta_{i j}$

The weight of the various indicators in the overall goal is in the Table 6.
The comparison of the calculated value and actual value, it is shown in Table 7.

Table 7. The comparison of the calculated value and actual value.

\begin{tabular}{|c|c|c|c|}
\hline Project & Result & & \\
\hline Subject & Name of the subject & $\left(\$\right.$ ten $_{\text {Proportion }}$ & \\
\hline No. & 336726.44 & actual & calculation \\
\hline 202 & Diplomacy & 0.001 & 0.034 \\
\hline 205 & Education & 0.153 & 0.282 \\
\hline 206 & Science and technology & 0.017 & 0.177 \\
\hline 20603 & Application research & 0.01630 & 0.052 \\
\hline 20604 & 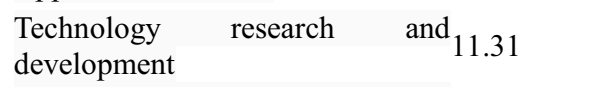 & 0.00004 & 0.095 \\
\hline 20605 & $\begin{array}{l}\text { Science and technology condition } \\
\text { and services }\end{array}$ & 0.00050 & 0.019 \\
\hline 20699 & $\begin{array}{l}\text { Other spending of science and } 47 \\
\text { technology }\end{array}$ & 0.00016 & 0.011 \\
\hline 207 & Sports culture and media & 0.794 & 0.368 \\
\hline 208 & Social security and employment $\quad 2602.71$ & 0.009 & 0.074 \\
\hline 20805 & $\begin{array}{l}\text { The reiteration administrative } \\
\text { institution }\end{array}$ & 0.009 & 0.074 \\
\hline 221 & The spending of housing security 7255.10 & 0.025 & 0.064 \\
\hline 22102 & $\begin{array}{l}\text { The spending of housing } \\
\text { reformation }\end{array}$ & 0.025 & 0.064 \\
\hline
\end{tabular}

\section{Conclusion}

Through the calculation of this paper, we determines the reasonable allocation proportion limit on the sports financial fund allocation, after comparing with the actual situation of fiscal expenditure in 2012, we found that the actual fiscal spending is not reasonable. Nearly $80 \%$ of the money went to the sports culture and the media [11]. However, education, scientific research and other aspects of the investment is too low. The investment is not reasonable and becoming a one-sided situation. This paper suggested that government should increase the investment of education, scientific research and foreign capital, at the same time, reducing the investment of sports culture and media. Thus it can make the fiscal expenditure allocation become more reasonable.

\section{References}

1. B. Liu, S.L. Hu, H.X. Xu, J.H. Gao, Chinese Journal of Health Policy. 2, 13-17 (2009).
2. D.C. Zhang, M. Li, China Sport Science. 33, 3-23 (2013).

3. J.T. Cai, B.Y. Fan, J.S. Wang, Journal of Beijing Sport University. (2009).

4. G.H. Wang, W.H. Zhang, Journal of Chengdu Physical Education Institute. 36, (2010).

5. J. Zhang, Y. Wu, Journal of Shanghai Physical Education Institute. 80-82 (2012).

6. Y. He, M. Xu, Journal of Chengdu Physical Education Institute. 33, 43-45 (2007).

7. Y. He, M. Xu, Journal of Wuhan Institute of Physical Education. 41, 40-42 (2007).

8. Y. Chen, G.S. Ma, China Sport Science and Technology. 45, (2009).

9. Y. He, M. Xu, Journal of Wuhan Institute of Physical Education. 41, 40-42 (2007).

10. H. Huang, Z.L. Liu, EBM 2010: International conference on engineering and business management. 1-8, 5186-5189 (2010).

11. S. Yan, Z. Jia, W. Liu, et al., Journal of Coastal Research. 73, 809-814 (2015). 